Ann. Biol. anim. Bioch. Biophys., 1978, 18 (3), 689-694

\title{
The influence of testosterone implantation in the brain and pituitary on pituitary gonadotropin levels in Atlantic Salmon parr
}

\author{
par L. W. CRIM, R. E. PETER *
}

Marine Sciences Research Laboratory, Memorial University of Newfoundland, St. John's, Newfoundland, AIC 557 Canada.

* Department of Zoology, University of Alberta, Edmonton, Alberta, T6G 2E9, Canada.

\begin{abstract}
Summary. Implantation of testosterone pellets in the brain or pituitary of male and female parr caused an increase in pituitary gonadotropin, and in males tended to stimulate spermatogenesis. The most effective implant locations were the nucleus lateral tuberis in the ventrobasal hypothalamus and the pituitary. This influence of testosterone on the brain and pituitary may be involved in control of precocious sexual maturation.
\end{abstract}

\section{Introduction.}

Precocious sexual maturity of Atlantic salmon parr occurs only in males (Jones, 1940). The prevalence of early maturity in some stocks of salmon may be related to the incidence of grilse parents in the population (Thorpe, 1975). The parr stage, identified by a series of pigmented bars along each side, is attained in the first year after hatching in freshwater. Smoltification terminates the parr stage in fish two years of age or older and they are then prepared for migration to the sea. Precocious maturity of parr males has importance for fisheries management because the phenomenon is associated with reduced growth rates and increased susceptibility to infection, and these young males are known to spawn with adult females returning from the sea.

The factors involved in control of precocious or early sexual maturation are poorly understood. Because of the role of steroid feedback in sexual maturation of mammals (Davidson, 1974), it was of particular interest in the present study to test for the possible influence of testicular androgens on the brain-pituitary axis in the onset or acceleration of precocious development in the salmon parr. We implanted testosterone pellets into various brain regions or the pituitary of Atlantic salmon parr and determined the effects on pituitary gonadotropin and gonadal activity.

\section{Materials and methods.}

Atlantic salmon parr, 1-3 years of age, were netted in mid-June 1976, near the time of onset of precocious development of the males, from Fitzgerald's Pond near 
Placentia Bay, Newfoundland. A very high incidence of early maturity (estimated in excess of 90 p. 100) for male Atlantic salmon of this population has been noted (Dalley E. L., personal communication). The fish were held in the laboratory in 227-I aquaria provided with a continuous supply of ambient freshwater and a simulated natural photoperiod. The fish were acclimated for a period of 14 days before use in the experiment. Fish weighing an average of $21.2 \mathrm{~g}(\mathrm{SD}=5.5)$ were selected for the experiment.

Prior to brain or pituitary implantation of a testosterone or blank (sham control) pellet, the fish were anesthetized with tricaine methane sulfonate $(1: 2,500)$ until opercular movements ceased. The surgical procedures and stereotaxic techniques previously developed for goldfish and killifish were followed (Peter, 1970 ; Peter, Macey and Gill, 1975). The sterotaxic holder developed for killifish was used for the salmon with the tip of the mouth bar positioned $1.0 \mathrm{~mm}$ anterior to the leading edges of the eye bars and the dorsal surface of the mouth bar $2.0 \mathrm{~mm}$ ventral to the grooves in the eye bars. Crystalline testosterone, 5.5 p. 100 by weight, was mixed with cocoa butter by warming to about $35^{\circ} \mathrm{C}$, and the pellets were prepared and implanted according to methods previously described (Billard and Peter, 1977). Individual pellets weighed an average of $14.3 \mu \mathrm{g}(\mathrm{SD}=2.8, \mathrm{~N}=15)$ and therefore contained about $0.8 \mu \mathrm{g}$ testosterone each. Pellets of cocoa butter alone were used as control. Pellets were implanted into selected brain regions or the pituitary using coordinates developed from photographs of Atlantic salmon serial brain sections (Peter and Crim, unpublished) as follows : optic tectum region, $0, \mathrm{~L} 1.0, \mathrm{D} 0.3$; nucleus preopticus region, +1.3 , $M, D 2.4$; nucleus lateral tuberis in the mediobasal hypothalamus, $+0.4, M, D 4.2$; and pituitary, $+0.6, M, D$ 5.5. Following the operation identification tags were attached to each fish just anterior to the dorsal fin. The fish were checked for spontaneous respiratory movements in a small recovery aquarium and then returned to the main aquaria. In some cases the gills were prefused with aquarium water to induce recovery from the anesthetic. During the experimental period, which lasted 7 days, the fish were fed live worms 3 times and they were bathed once with Terramycin (Pfizer), $2 \mathrm{~g} / 37.8 \mathrm{l}$.

Because sexing of young Atlantic salmon is impossible by external observations, a large number of fish (total of 115 individuals) were used in this study. 78 fish were implanted with testosterone pellets, and 37 received blank cocoa butter pellets or served as intact controls. Deaths or severe fungus infections causes a 10 p. 100 loss in fish numbers. Of the 35 male and 33 female fish implanted with testosterone and surviving the length of the experiment, 5 males and 2 females were noted with misplaced pellets and the data were discarded.

On the days of autopsy (July 13-17, 1976) fish were anesthetized and blood samples were withdrawn from the caudal vasculature into heparinized syringes. Plasma samples were stored at $-20^{\circ} \mathrm{C}$. Pituitaries were removed and immediately frozen on small aluminum strips over dry ice. Following storage at $-20^{\circ} \mathrm{C}$, pituitaries were lyophilized to dryness, weighed to the nearest $0.1 \mu \mathrm{g}$, and homogenized in $1 \mathrm{ml}$ barbital buffer, $0.8 \mathrm{M}, \mathrm{pH} 8.6$, using small glass homogenizers. The supernatant was recovered after centrifugation and stored at $-20^{\circ} \mathrm{C}$. The brain and gonads were placed in Bouin's fluid. Pellet locations for nucleus lateral tuberis and pituitary targets were determined by gross steromicroscopic examination at the time of autopsy. The 
accuracy of all brain pellet locations was further checked using serial microscopic sections of the brain. An estimate of the spermatogenic development of the testes was determined by microscopic examination of the gonad. The results were analyzed according to the final location of the pellets. Pituitary and plasma gonadotropin was determined using a radioimmunoassay specific for salmonid gonadotropin (Crim, Watts and Evans, 1975) and parallel responses, compared with the standard employed, were obtained with most Atlantic salmon parr pituitaries excepting the female pituitaries of very low gonadotropin potency. The results were compared using student's « $\dagger$ » test.

\section{Results.}

The control males that received a cocoa butter pellet in various areas (nucleus preopticus, nucleus lateral tuberis or pituitary, $N=10$ ) and three intact males were pooled for analysis. In 5 of these 13 fish no pituitary gonadotropin was detectable. For the remaining 8 fish in the group the mean values for pituitary gonadotropin content and pituitary gonadotropin concentration were significantly lower $(P<0.01)$ than the values for fish receiving testosterone implants in the brain or pituitary (table 1). Males implanted with testosterone in the optic tectum provided a base-line pituitary gonadotropin level for comparison with the other testosterone implanted groups (table 1), as the optic tectum is an unlikely brain region for steroid feedback receptors. The fact that the males implanted with testosterone in the optic tectum had significantly greater pituitary gonadotropin, than in the combined intact-cocoa butter implant groups, indicates that the dose of testosterone included in the pellets must have diffused or been otherwise transported to an effective feedback site elsewhere, either in the brain or the pituitary. In comparison with the optic tectum group (table 1), there was no effect on pituitary gonadotropin due to testosterone implantation in the nucleus preopticus region. In contrast, pituitary gonadotropin was significantly greater

TABLE 1

Effects of brain and pifuitary implants of cocoa butfer or festosterone on pituitary gonadotropin levels in male Atlantic salmon porr

\begin{tabular}{|c|c|c|c|c|}
\hline \multirow{2}{*}{$\begin{array}{c}\text { Location of } \\
\text { pellet }\end{array}$} & \multirow[b]{2}{*}{ Treatment } & \multirow[b]{2}{*}{$N$} & \multicolumn{2}{|c|}{ Pituitary $\mathrm{G}+\mathrm{H} a$} \\
\hline & & & $\begin{array}{l}\text { Content } \\
\mathrm{ng} / \mathrm{pit} \text {. }\end{array}$ & $\begin{array}{c}\text { Concentration } \\
\mathrm{Pg} / \mu \mathrm{g}\end{array}$ \\
\hline $\begin{array}{l}\text { Combined locations } \ldots \ldots \ldots \ldots \\
\text { Optic tectum } \ldots . . . \ldots \ldots \ldots \\
\text { Nucleus preopticus } \ldots \ldots \ldots \ldots \\
\text { Nucleus lateral tuberis } \ldots \ldots \ldots \\
\text { Pituitary } \ldots \ldots \ldots \ldots \ldots \ldots \ldots\end{array}$ & $\begin{array}{l}\text { Cocoa butter } \\
\text { Testosterone } \\
\text { Testosterone } \\
\text { Testosterone } \\
\text { Testosterone }\end{array}$ & $\begin{array}{r}8 \\
7 \\
5 \\
5 \\
13\end{array}$ & $\begin{aligned} 2.8 \pm 0.6 b \\
11.8 \pm 2.4 \\
9.9 \pm 1.3 \\
34.6 \pm 5.6 * c \\
40.1 \pm 8.8 * c\end{aligned}$ & $\begin{array}{l}55.4 \pm 7.7 b \\
163 \pm 30 \\
134 \pm 27 \\
475 \pm 103 * c \\
421 \pm 84 * c\end{array}$ \\
\hline
\end{tabular}

$a$ Values are $\overline{\mathbf{x}} \pm \mathrm{SE}$.

$b$ Significance compared to testosterone treatment : $\mathbf{P}<0.01$

c Significance compared to optic tectum control : *, $\mathrm{p}<0.05 ; * *$. $\mathrm{p}<0.01$. 
in males receiving testosterone implants in the nucleus lateral tuberis region in the ventrobasal hypothalamus or the pituitary (table 1).

Low pituitary gonadotropin values, mean pituitary content and mean pituitary concentration were observed for a randomly selected subsample of control female salmon which were implanted with cocoa butter in either the pituitary or the nucleus preopticus. Pituitary gonadotropic hormone increased significantly $(P<0.01)$ when immature female salmon received testosterone implants irrespective of implant sites (table 2). Like the male salmon, the most effective testosterone implant locations in females were the pituitary and the nucleus lateral tuberis region in the ventrobasal hypothalamus $(P<0.01)$.

TABLE 2

Effects of brain and pituitary implants of cocoa butter or testosterone on pituitary gonadotropin levels in female Atlontic salmon parr

\begin{tabular}{|c|c|c|c|c|}
\hline \multirow{2}{*}{$\begin{array}{c}\text { Location of } \\
\text { pellet }\end{array}$} & \multirow[b]{2}{*}{ Treatment } & \multirow[b]{2}{*}{$N$} & \multicolumn{2}{|c|}{ Pituitary GtH $\left({ }^{a}\right)$} \\
\hline & & & $\begin{array}{l}\text { Content } \\
\text { ng/pit. }\end{array}$ & $\begin{array}{c}\text { Concentration } \\
\mathrm{pg} / \mu \mathrm{g}\end{array}$ \\
\hline 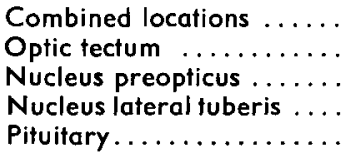 & $\begin{array}{l}\text { Cocoa butter } \\
\text { Testosterone } \\
\text { Testosterone } \\
\text { Testosterone } \\
\text { Testosterone }\end{array}$ & $\begin{array}{r}7 \\
9 \\
5 \\
3 \\
14\end{array}$ & $\begin{array}{l}0.8 \pm 0.2^{b} \\
4.0 \pm 0.6 \\
6.3 \pm 1.4 \\
24.4 \pm 6.6 * * * c \\
25.3 \pm 3.8 * * * c\end{array}$ & $\begin{array}{l}11.9 \pm 1.3 b \\
52.1 \pm 12.8 \\
112 \pm 50 * c \\
336 \pm 58 * * * c \\
318 \pm 48 * * * c\end{array}$ \\
\hline
\end{tabular}

a Values are $\overline{\mathrm{X}} \pm \mathrm{SE}$.

$b$ Significance compared to testosterone treatment : $p<0.01$.

c Significance compared to optic fectum control : *, $\mathrm{p}<0.05 ; * * *, \mathrm{p}<0.001$.

Plasma collected from male and female salmon parr produced no significant response in the radioimmunoassay. Circulating gonadotropin levels in both control and treated fish were therefore less than $0.2 \mathrm{ng} / \mathrm{ml}$ of plasma, the limit of sensitivity for the salmon gonadotropin radioimmunoassay.

Microscopic examination of testes sections from gonads collected at this early stage of the reproductive season revealed that a variable degree of spermatogenic development was present in all experimental groups of males. However, 63 p. 100 of the males that received a testosterone implant had advanced beyond the resting spermatogonia to the spermatocyte and/or spermatid stage. Only $38 \mathrm{p} .100$ of the combined unimplanted - cocoa butter implanted groups had advanced beyond the spermatogonia stage. Control males with undetectable pituitary gonadotropin levels had inactive gonads with only resting spermatogonia present in the testes. In control or testosterone implanted female salmon parr there was no evidence of ovarian development.

\section{Discussion and conclusion.}

Significant increases in pituitary gonadotropin in both male and female Atlantic salmon parr following brain or pituitary implantation of testosterone indicates that 
testosterone has an effect to increase gonadotropin accumulation in fish of both sexes at this particular stage. The effect of testosterone implanted in any location in males always tended to be greater, and in some cases was significantly greater, than in the females. Greater pituitary gonadotropin accumulation in the male parr could result from their relatively advanced state of maturity or they might be more responsive to testosterone. This is of interest because the plasma levels of testosterone and 11-keto-testosterone in female teleosts are substantial, and in some species equal to levels found in males (Campbell, Walsh and Idler, 1976 ; Katz and Eckstein, 1974 ; Schreck and Hopwood, 1974 ; Wingfield and Grimm, 1977). Within each sex (tables 1 and 2) testosterone implants in the nucleus lateral tuberis region and the pituitary were more effective than preoptic or optic tectum implants, indicating that these are the effective sites for stimulation by testosterone. This fits with earlier findings showing that the effective site for negative feedback by estrogens in goldfish with a mature ovary is primarily the pituitary, with the nucleus lateral tuberis region being a less effective site (Billard and Peter, 1977). Also, the binding of testosterone to cells in the nucleus lateral tuberis and pituitary in male green sunfish has been demonstrated by radioautography (Davis, Morrell and Pfaff, 1977).

Since plasma gonadotropin was not detectable in the male or female Atlantic salmon parr using the present GtH radioimmunoassay procedure, the influence of testosterone, if any, on $\mathrm{GHH}$ secretion is unknown. Testosterone does have a stimulatory effect upon the pituitary accumulation of gonadotropin and the supporting evidence can be summarized as follows :

1. Elevated pituitary gonadotropin levels can be induced in those fish which normally have extremely low levels or no detectable pituitary gonadotropin. Pituitaries of sexually immature male control fish were devoid of gonadotropin activity and very low levels were observed for pituitaries of control immature female parr. Since the gonadotropin potency of female pituitaries remains uniformly low throughout the year (Crim and Evans, 1978), it was surprising to find elevated levels of gonadotropin in Atlantic salmon female parr treated with testosterone. Similar increases in gonadotropin were observed after testosterone implantation of males which remained sexually immature at the termination of the experimental period.

2. Pituitary gonadotropin levels are elevated in precocious male parr which have been treated with small quantities of testosterone. Testicular activity was apparently more advanced in a greater proportion of the androgen treated males compared with the control group of fish.

3. Pituitary gonadotropin levels are greatly increased in the ripe male Atlantic salmon parr (Crim and Evans, 1978), and the presence of high androgen levels are also to be expected. Elevated plasma gonadotropin levels have been reported for the mature adult male salmon (Crim, Watts and Evans, 1975), and substantial quantities of androgen are also known to be present at this advanced stage of sexual development (Idler, Horne and Sangalang, 1971).

The increased pituitary gonadotropin in males with a brain or pituitary implant of testosterone, coupled with the greater proportion of males that commenced spermatogenesis, indicates that precocious sexual maturation was apparently advanced by the testosterone treatment of the immature parr. Whether testicular androgens 
also have an influence on the onset of precocious sexual development in male parr under normal conditions cannot be discerned by the present study, but our results suggest that it may be a part of the mechanism. The lack of evidence for ovarian development in the females suggests that gonadotropin secretion was insufficient or other physiological conditions were not appropriate for the ovaries to respond.

Reçu en octobre 1977.

Accepté en janvier 1978.

Acknowledgments. - The authors wish to thank B. Abbott and D. Evans for technical assistance and E. Dalley and M. O'Connell for salmon collections. This work was supported by the National Research Council of Canada with grants \# A-9729 to L. Crim and \# A-6371 to R. Peter. MSRL Contribution Number 274.

Résumé. Des implants de testostérone placés dans le cerveau et l'hypophyse de parrs mâle et femelle induisent une augmentation de gonadotropine hypophysaire, et chez les mâles tendent à stimuler la spermatogenèse. La localisation la plus efficace se trouve dans l'hypothalamus ventrobasal (nucleus latéral tuberis) et dans l'hypophyse. Cette influence de la testostérone sur le cerveau ef l'hypophyse peut être impliquée dans la maturation sexuelle précoce.

\section{References}

BILLARD R., PETER R. E., 1977. Gonadotropin release after implantation of anti-estrogen in the pituitary and hypothalamus of goldfish, Carassius auratus. Gen. comp. Endocrinol., 32, 213-220.

CAMPBELL C. M., WALSH J. M., IDLER D. R., 1976. Steroids in the plasma of the winter flounder (Pseudopleuronectes americanus Walbaum). A seasonal study and investigation of steroid involvement in oocyte maturation. Gen. comp. Endocrinol., 29, 14-20.

CRIM L. W., EVANS D. M., 1978. Seasonal levels of pituitary and plasma gonadotropin in male and female Atlantic salmon parr. Can. J. Zool. (in press.).

CRIM L. W., WATTS E. G., EVANS D. M., 1975. The plasma gonadotropin profile during sexual maturation in a variety to salmonid fishes. Gen. comp. Endocrinol., 27, 62-70.

DAVIDSON J. M., 1974. Hypothalamic-Pituitary regulation of puberty, evidence from animal experimentation, 79-103. In, GRUMBACH M. M., GRAVE G. D., MAYER F. E., The control of the onset of puberly. John Wiley and Sons, N. Y.

DAVIS R. E., MORRELL J. I., PFAFF D. W., 1977. Autoradiographic localization of sex steroid concentrating cells in the brain of the teleost Macropodus opercularis (Osteichthyes : Belontiidae). Gen. comp. Endocrinol., 33, 496-505.

JONES J. W., 1940. Histological changes in the testis in the sexual cycle of male salmon parr (Salmo salar L. juv.). Proc. roy. Soc. Ser. B., 128, 499-509.

IDLER D. R., HORNE D. A., SANGALANG G. B., 1971. Identification and quantification of the major androgens in testicular and peripheral plasma of Atlantic salmon (Salmo salar) during sexual maturation. Gen. comp. Endocrinol., 16, 257-267.

KATZ Y., ECKSTEIN B., 1974. Changes in steroid concentration in blood of female Tilapia aurea (Teleostei, Cichlidae) during initiation of spawning. Endocrinology, 95, 963-967.

PETER R. E., 1970. Hypothalamic control of thyroid gland activity and gonadal activity in the goldfish, Carrassius auratus. Gen. comp. Endocrinol., 14, 334-356.

PETER R. E., MACEY M. J., GILL V. E., 1975. A stereotaxic atlas and technique for forebrain nuclei of the killifish, Fundulus heteroclitus. J. comp. Neurol., 159, 103-127.

SCHRECK C. B., HOPWOOD M. L., 1974. Seasonal androgen and estrogen patterns in the goldfish, Carassius auratus. Trans. amer. Fish. Soc., 103, 375-378.

THORPE J. E., 1975. Early maturity in male Atlantic salmon. Scot. Fish. Bull., 42, 15-17.

WINGFIELD J. C., GRIMM A. S., 1977. Seasonal changes in plasma cortisol, testosterone and ostradiol-17 $\beta$ in the plaice, Pleuronectes platessa L. Gen. comp. Endocrinol., 31, 1-11. 